the information. If this relationship is undermined by the type of behaviour described by Dr Griffin it is difficult to see the advantages of disclosing doctors' identities.

The department's medical staff do follow up a number of reports, and this is done with due regard for the pressures on reporting doctors and the complex confidentiality and legal issues inherent in adverse reaction reporting.

G JONES

Committee on Safety of Medicines,

Department of Health and Social Security, London SW8 5NG

1 Mann RD. Adoerse drug reactions. London: Parthenon Publishing (in press).

\section{Adverse reaction monitoring using cohort identification}

SIR,-We agree with Dr J P Griffin (28 February, p 576) that the sensitivity of prescription event monitoring using cohorts of up to 20000 patients may not be sufficient to detect adverse reactions that occur at a frequency of less than one per 1000 . The numbers of patients followed up by such monitoring are determined not by the system itself but by the number of questionnaires doctors are prepared to complete.

Dr Griffin proposes a scheme of cohort identification for all new drugs marketed in general practice. As with prescription event monitoring, cohorts of up to 100000 patients would be identified and used, retrospectively, only if it became necessary to test a hypothesis about specific adverse reactions. We have been doing precisely this for a limited number of drugs since 1981 . In addition to 19 standard prescription event monitoring studies we have stored the details of large cohorts of patients treated with eight other drugs. Thus more than 700000 prescriptions have been stored in case a serious problem requires investigation later.

Unfortunately, banking large cohorts of patients is not as simple or inexpensive as Dr Griffin suggests. When an established drug is used on a very large scale a cohort of users may be identified by collecting prescriptions for the whole country during a short period, with each prescription identifying a single patient. (If prescriptions are collected for longer periods most are repeats.)

Few drugs rapidly achieve use by as many as 100000 patients. For example, a drug that is prescribed monthly for a chronic disease usually achieves sales equivalent to the addition of 20000 new patients during each of the first five years of marketing, and thus more than three million prescriptions would have to be collected to identify 100000 patients. The Prescription Pricing Authority cannot include the patient's name or address on computer record, and we estimate that 45 operator years of work by our experienced clerks would be required to process three million prescriptions even before questionnaires could be sent to doctors. If all doctors returned their questionnaires we would expect to find that about 30000 patients had moved to a new practice and if the drug was a non-steroidal anti-inflammatory or hypotensive one that about 15000 had died by the time 100000 patients had been assembled.

We have used prescription event monitoring on several occasions and have achieved response rates exceeding $75 \%$. It would be wasteful to duplicate the procedure for collecting prescriptions, which is already conducted for all new drugs during the first few years of marketing. A case could be made, howivever, for taking a 100000 patient sample as soon as sales reached the point when a one patient, one prescription sample was possible. The Drug
Safety Research Unit could store these samples and launch an investigation whenever the Committee on Safety of Medicines requested one.

Measured by its ability to collect large cohorts of patients treated with any one drug, prescription event monitoring is already 10 times larger than any other scheme in the world. It is entirely complementary to the yellow card scheme, and it seems very unlikely that either will be replaced by record linkage schemes, however desirable this might be in the distant future. The only barrier to the expansion of such monitoring is the workload on the Prescription Pricing Authority and general practitioners.

Drug Safety Research Unit, Southampton $\mathrm{SO} 32 \mathrm{BX}$

WILliam H W INMAN NIGEL S B RAWSON

Father fails in attempt to stop girlfriend's abortion

SIR,-Your legal correspondent rightly reported the appeal court judges' astonishment that Oxfordshire Health Authority would not proceed with the termination of pregnancy in this very sad and difficult case until a decision of the House of Lords was known (7 March, p 631). However, not all the facts were available to the court when the judges expressed that view.

The health authority's officers had been told that, should the appeal fail, means had already been found that (should leave to appeal be granted) the case would be heard in the House of Lords the next day. This information was not available to the Appeal Court judges when they expressed surprise. The authority's officers were simply trying to act as best they could in difficult circumstances in seeing that medical staff were advised of the legal position and were not rushed into taking decisions that they might feel required further discussion with the patient.

In the end, it is surely the doctor-patient relationship and not the speed of reaction to decisions of the court that should govern what is done, and when, in such a difficult situation-as happened in this particular case.

C H PaINe

Oxfordshire Health Authority, Oxford OX3 9DZ

\section{Neuropathy of the feet due to running on cold surfaces}

SIR,-Mr M Reichl's report (7 February, p 348) highlights once again the public's ignorance of the potential dangers of the cold. Even hardy and fit karate exponents are not impervious to its effects.

The distribution of the skin injury in the illustrated example certainly suggests that the blisters corresponded to the weight bearing surfaces of the feet. As no pain was experienced during running a cold induced local peripheral neuropathy, rather than the direct effects of the cold, presumably contributed to the development of blisters. The description of "bright red soles" implies rewarming hyperaemic vasodilatation, which suggests that a cold thermal injury had been inflicted, and this might have compounded the blistering in addition to blocking nerve conduction.

The report does not refer to the wind chill factor Running at a speed of $16 \mathrm{~km} / \mathrm{h}$ would effectively lower the reported ambient air temperature of $-5^{\circ} \mathrm{C}$ to $-14^{\circ} \mathrm{C}$. Any prevailing wind would have further reduced the effective environmental temperature to even more dangerous levels.
Few risk factors for the development of local cold injury have been identified,' and several questions arise from $\mathrm{Mr}$ Reichl's report. What features made the 25 casualties more susceptible than the 135 who did not report sick? Did any runners of Negro origin (a high risk group ${ }^{2}$ ) compete, and if so how did they fare? Were the sufferers the slower runners, whose injuries occurred because of prolonged contact with cold surfaces, or were they the faster runners, who would have created a greater wind chill factor and friction? Did the patients experience severe paraesthesia on rewarming, a constant feature of non-freezing cold injury?

The real message of $\mathrm{Mr}$ Reichl's report is the need to educate the public in the potentially damaging effects of even brief exposure to the less than extreme temperatures of a British winter.

T R WHELAN R P CRAIG

Department of Surgery,

British Military Hospital,

Rinteln,

West Germany

Craig RP. Military cold injury during the war in the Falkland Islands 1982: an evaluation of possible risk factors. $\mathcal{J} R A r m y$ Med Corps 1984;130:89-96.

2 Miller D, Bjornson DR. An investigation of cold injured soldiers in Alaska. Milit Med 1962;127:247-52.

Future of the pathologist in an era of technological change and cost containment

SIR,-Dr G W Pennington (21 February, p 521) has highlighted the increased pressure on laboratory budgets engendered by the current cost cutting climate in the National Health Service. One part of the laboratory budget that attracts a disproportionate amount of attention is the on call service, as it is widely believed to be abused. Furthermore, the additional labour costs of on call work are easily identified, and it is often assumed that if the amount of work could be reduced expenditure would decrease proportionately.

We tested this by examining the 467 analytical requests relating to patients at this hospital that were sent out of hours to the clinical chemistry department over 18 days, which included three weekends. The notes for these patients were examined to ascertain the reasons for making the request. A request was considered justified if it could be shown that, in view of the clinical circumstances when the request was made, there was a reasonable chance that the results of the investigation would show or exclude a clinically important abnormality requiring action.

We determined the financial consequences of reducing requests by examining the laboratory on call records. The regulations governing payment for on call work mean that there is no financial saving unless all requests in a call period are eliminated. At this busy district general hospital a mean of 2.5 requests were dealt with during each call period, and thus each request attracted an on call labour cost (including standby) of $£ 4.01$. We then calculated the effect on the on call budget of two strategies. The first eliminated all requests that we considered to be unjustified or that could have waited until the next working day. This resulted in a $16 \%$ reduction in requests but only a $4 \cdot 6 \%$ reduction in on call labour costs. With the second strategy all routine monitoring, preoperative, or screening investigations were eliminated. This decreased the workload by $44 \%$ but reduced on call labour costs by only $18 \%$, with the cost of each request rising to $£ 5 \cdot 90$.

We have shown that there is little abuse of the out of hours laboratory service at this hospital and conclude that reductions in the on call workload 